\title{
Adaptação, Produtividade e Persistência de Arachis pintoi Submetido a Diferentes Níveis de Sombreamento ${ }^{1}$
}

\author{
Carlos Maurício Soares de Andrade ${ }^{2}$, Judson Ferreira Valentim ${ }^{3}$
}

RESUMO - Este experimento foi realizado com o objetivo de determinar o potencial forrageiro da leguminosa Arachis pintoi, submetida a 0,30, 50 e 70\% de sombreamento, em sistemas silvipastoris e como cobertura do solo em sistemas agroflorestais. O delineamento experimental usado foi o inteiramente casualizado, com quatro repetições. Realizou-se uma avaliação no final do período chuvoso e outra no final do período seco, usando as características altura e vigor de plantas, cobertura do solo e biomassa aérea, subterrânea e total. Os resultados mostraram que $A$. pintoi apresentou boa adaptação e persistência nos níveis de sombreamento estudados. A produtividade, apesar de ter diminuído com o aumento dos níveis de sombreamento, foi considerada adequada mesmo nos níveis mais altos. Concluiu-se que é possível usar esta leguminosa como cobertura do solo em sistemas agroflorestais e como forrageira em sistemas silvipastoris.

Palavras-chave: amendoim forrageiro, Arachis pintoi, cobertura do solo, leguminosa, sistemas agroflorestais, sistemas silvipastoris, sombreamento

\section{Adaptation, Productivity and Persistence of Arachis pintoi under Different Levels of Shading}

\begin{abstract}
The experiment was conducted to determine the forage potential of the Arachis pintoi submitted to $0,30,50$ and $70 \%$ of shading, in silvopastoral systems and as ground cover in agroforestry systems. The experimental design was a completely randomized design with four replications. An evaluation was carried at the end of the rainy season and another at the end of the dry season, using the caracteristics height and plant vigor, ground cover, and total, above and below ground biomass. The results showed that A. pintoi presented good adaptation and persistence in the studied levels of shading. Although its productivity decreased with the increase of the levels of shading, it was considered adequate, even in the highest levels of shading. This indicates that it is possible to use this legume as ground cover in agroforestry systems and as forage in silvopastoral systems.
\end{abstract}

Key Words: forage peanut, Arachis pintoi, ground cover, legume, agroforestry systems, silvopastoral systems, shade

\section{Introdução}

Nos últimos anos, a área cultivada com sistemas agroflorestais (SAF's) no Estado do Acre vem apresentando grande expansão. Estes sistemas parecem ser excelente alternativa para a produção sustentável de alimentos na Amazônia, por apresentarem maior diversidade de espécies e promoverem maior equilíbrio do ecossistema, ao contrário do que ocorre com as monoculturas em geral. Porém, nos primeiros anos de sua implantação, os SAF's apresentam problemas de perda de solo e de nutrientes, causados pela erosão e lixiviação, e elevada incidência de plantas invasoras, que demandam grande quantidade de mão-de-obra para o seu controle. Uma alternativa para contornar estes problemas é o uso de leguminosas como cobertura do solo (ANDRADE e VALENTIM, 1996), o que possibilita também a produção de forragem e o estabelecimento de sistemas silvipastoris.
A leguminosa Arachis pintoi, com ciclo de vida perene e hábito de crescimento estolonífero, tem mostrado grande potencial como cobertura do solo em vários sistemas agrícolas (CRUZ et al., 1994). Segundo SKERMAN (1977), um dos principais fatores responsáveis pela persistência da leguminosa como cobertura do solo é a sua tolerância ao sombreamento causado pelas culturas perenes. De acordo com PIZARRO e RINCÓN (1994), A. pintoi possui duas características que contribuem para o seu sucesso como cultivo de cobertura e proteção do solo: a habilidade de crescersob sombreamento e a densa camada de estolões enraizados que protegem o solo dos efeitos erosivos das chuvas pesadas. Além disso, quando comparada com outras leguminosas tradicionalmente utilizadas como cobertura do solo, $A$. pintoi tem a vantagem de não possuir o hábito de crescimento trepador, o que reduz os custos de manutenção (CRUZ et al., 1994).

No Acre, o acesso de A. pintoi BRA-031143 apre-

\footnotetext{
1 Estudo financiado pela EMBRAPA/Projeto ASB.

2 Eng. Agr ${ }^{\circ}$., B. Sc., Bolsista do CNPq. EMBRAPA - Acre, Cx. P. 392, CEP 69901-180, Rio Branco, AC.

${ }^{3}$ Eng. Agro., Ph. D., Pesquisador da EMBRAPA - Acre.
} 
sentou excelente produtividade de forragem, superior a todos os demais acessos avaliados, com média anual de $18.000 \mathrm{~kg}$ de matéria seca/ha (VALENTIM, 1997). A forragem de Arachis spp. apresenta excelente valor nutritivo, com teores de proteína bruta e digestibilidade in vitro da matéria seca variando de 13 a $25 \%$ e de 60 a $67 \%$, respectivamente (LASCANO, 1994).

Este trabalho teve como objetivo avaliar a adaptação, produtividade e persistência da leguminosa A. pintoi, quando submetida a diferentes níveis de sombreamento, visando ao uso múltiplo desta espécie como forrageira em sistemas silvipastoris e como cobertura do solo em sistemas agroflorestais.

\section{Material e Métodos}

O experimento foi conduzido no Campo Experimental da Embrapa-Acre. O ecossistema da região é de floresta tropical úmida, com altitude de $160 \mathrm{~m}$. O solo foi classificado como Podzólico Vermelho Amarelo. Os dados climáticos do local são apresentados na Figura 1.

O delineamento experimental utilizado foi o inteiramente casualizado, com quatro repetições. Os tratamentos consistiram de quatro níveis de sombreamento $(0,30,50$ e $70 \%)$, obtidos com a utilização de telas de polipropileno pretas (sombrite), sendo que a testemunha foi mantida a pleno sol. As parcelas experimentais tinham dimensões de $3 \times 2 \mathrm{~m}$, com área útil de $2 \mathrm{~m}^{2}$. As telas com dimensões de $4 \times 3 \mathrm{~m}$ foram fixadas, em armações de madeira, a $70 \mathrm{~cm}$ do solo.

Os tratamentos foram aplicados em área já estabelecida com A pintoi BRA-031143, de modo a reproduzir uma situação em que a leguminosa tivesse sido plantada junto com as espécies arbóreas componentes do SAF. Assim, cada nível de sombreamento representaria um estádio de desenvolvimento do SAF.

O experimento foi implantado em dezembro de 1995. Nesta ocasião foi feito um corte de uniformização da leguminosa a $5 \mathrm{~cm}$ dealtura e realizado o arranquio manual das invasoras presentes na área. Logo após a primeira avaliação (maio/96), repetiu-se o corte de uniformização e o controle das invasoras. Realizou-se uma avaliação no final do período chuvoso (maio/96) e outra no final do período seco (outubro/96). As características avaliadas foram: a) vigor das plantas; b) cobertura do solo; c) altura das plantas; e d) biomassa aérea, subterrânea e total.

O vigor das plantas foi avaliado por meio de observações visuais usando a seguinte escala: 1 - péssimo; 2 -ruim; 3 - regular; 4 - bom; e, 5 - excelente. A cobertura do solo foi avaliada utilizando a seguinte escala: 1 - 0 a $20 \%$; 2 21 a $40 \%$; 3 - 41 a $60 \%$; 4 - 61 a $80 \%$; e, 5 - 81 a $100 \%$. A altura média das plantas ("stand") foi determinada mensalmente, sendo quenos meses de junhoejulhonão foi possível realizar a coleta dos dados. A biomassa aérea foi
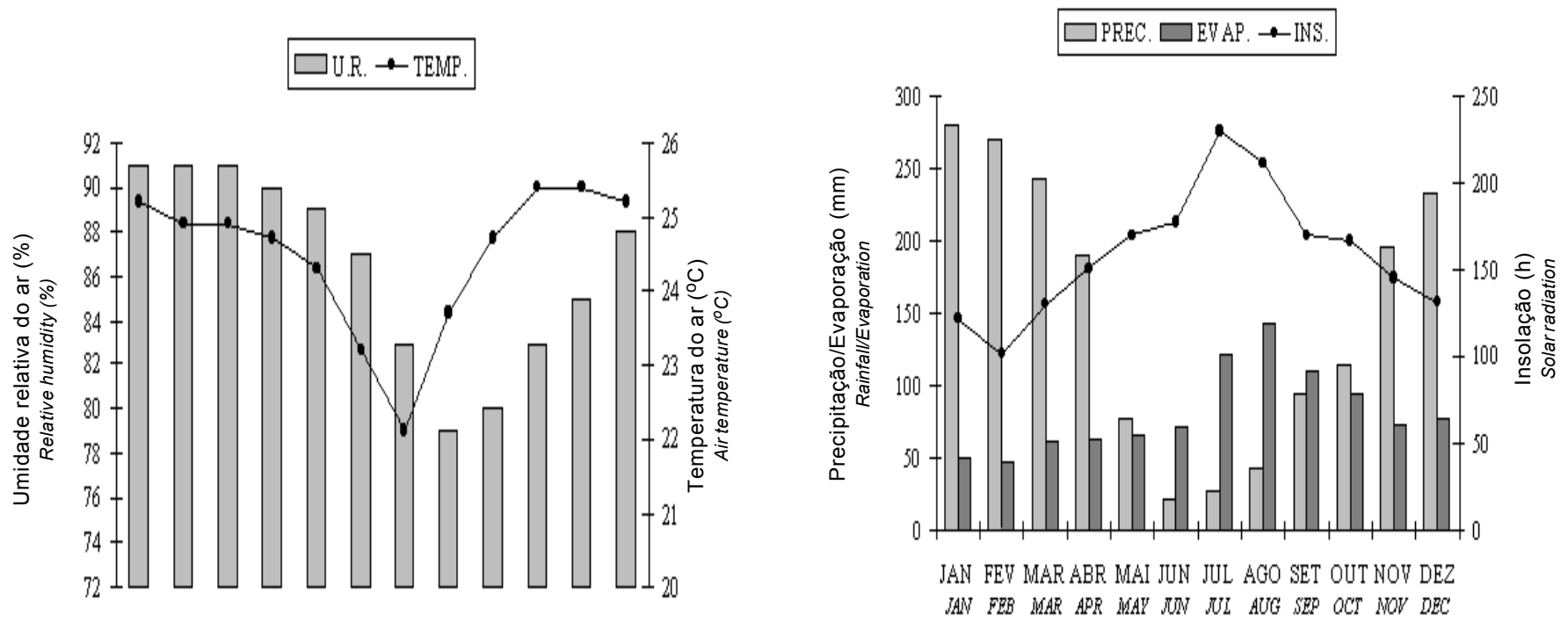

Figura 1 - Médias dos dados climáticos do Campo Experimental da Embrapa-Acre, no período de 1990 a 1995, em Rio Branco, Acre.

Figure 1 - Means of the climatic data of the Experimental Station of Embrapa-Acre, from 1990 to 1995, in Rio Branco, Acre.

Fonte: $\quad$ Estação Agrometeorológica da Embrapa-Acre.

Source: Agrometeorological Station of Embrapa-Acre. 
determinada em área de $0,15 \mathrm{~m}^{2}$, cortando-se as plantas rente ao solo, coletando-se inclusive os estolões. Após a coleta das amostras, foi feita a separação da biomassa aérea de $A$. pintoi da biomassa das invasoras. As amostras foram então colocadas para secar, a $70^{\circ} \mathrm{C}$, em estufa com circulação forçada de ar, durante 72 horas. A biomassa subterrânea foi determinada, coletando-se uma porção de solo, de aproximadamente $20 \mathrm{~cm}$ de profundidade, da área onde foi amostrada a biomassa aérea $(30 \times 50 \mathrm{~cm})$. Cada porção de solo foi lavada em peneiras para a retirada do sistema radicular, que foi colocado para secar, a $70^{\circ} \mathrm{C}$, em estufa, durante 72 horas. Após a secagem, as amostras foram pesadas em balança de precisão, e os dados foram extrapolados para $\mathrm{kg}$ de matéria seca/ha. Os dados foram submetidos à análise de regressão, pelo método dos quadrados mínimos, utilizando-se o procedimento REG do programa SAS (SAS, 1989).

\section{Resultados e Discussão}

\section{Produtividade}

Para a biomassa aérea de $A$. pintoi, houve efeito linear negativo, com os níveis de sombreamento, no período chuvoso $(\mathrm{P}<0,001)$ (Figura $2 \mathrm{a})$, e positivo no período seco $(\mathrm{P}<0,05)$ (Figura $2 \mathrm{~b})$. Na média dos dois períodos, as plantas submetidas a 30, 50 e $70 \%$ de sombreamento produziram, respectivamente, $92,86 \mathrm{e}$ $85 \%$ da biomassa aérea produzida pela testemunha (Tabela 1a).
Esta pequena redução da produção de biomassa aérea mostra que esta leguminosa possui boa capacidade de produção de forragem, mesmo nos maiores níveis de sombreamento, concordando com as afirmações de PIZARRO e RINCÓN (1994). Além disso, com 50 e $70 \%$ de sombreamento, houve melhor distribuição sazonal da produção de biomassa aérea (Tabela 1a), sendo este fator de grande importância, por propiciar maior estabilidade da produção de forragem e da cobertura do solo, durante o ano.

Já para a biomassa subterrânea, houve efeito linear negativo tanto no período chuvoso $(\mathrm{P}<0,01)$ (Figura 2a), como no período seco $(\mathrm{P}<0,01)$ (Figura $2 \mathrm{~b}$ ). $\mathrm{Na}$ média dos dois períodos, as plantas submetidas a 30 , 50 e $70 \%$ de sombreamento produziram, respectivamente, 85,62 e 45\% da biomassa subterrânea produzida pela testemunha (Tabela 1b). Esta redução da biomassa subterrânea das plantas mais sombreadas pode influenciar a sua capacidade de recuperação, quando submetida a regimes mais intensos de corte ou sob pastejo direto.

Quanto à biomassa total, houve efeito linear negativo apenas no período chuvoso $(\mathrm{P}<0,001)$ (Figura $2 \mathrm{a}$ ). Em outubro, o sombreamento teve pouca influência sobre a biomassa total de $A$. pintoi, com BT equivalente a $\overline{\mathrm{Y}}=7002,0 \mathrm{~kg}$ de matéria seca/ha. A produção de biomassa total das plantas submetidas a 30,50 e $70 \%$ de sombreamento, na média dos dois períodos, foi, respectivamente, de 89, 74 e $65 \%$ da produção da testemunha (Tabela 1c).

As diferenças ocorridas entre os tratamentos quanto

Tabela 1 - Produção e variação sazonal (VS) da biomassa de $A$. pintoi, submetido a diferentes níveis de sombreamento, no final do período chuvoso (Mai/96) e do período seco (Out/96)

Table 1 - Yield and seasonal variation (SV) of the biomass of A. pintoi, submitted to different levels of shading, at the end of the rainy season (May/96) and dry season (Oct/96)

Nível de sombra, \% (a) Biomassa aérea (kg/MS.ha)

Level of shade

Above ground biomass (kg/DM.ha)

\begin{tabular}{lccccc} 
& Maio/96 & Out/96 & VS & Média & $\%$ \\
& May & Oct & SV & Mean & \\
\hline 0 & 6068 & 2303 & $-62 \%$ & 4185 & 100 \\
30 & 5078 & 2644 & $-48 \%$ & 3861 & 92 \\
50 & 3790 & 3397 & $-10 \%$ & 3594 & 86 \\
70 & 3029 & 4062 & $+34 \%$ & 3546 & 85 \\
\hline
\end{tabular}

\begin{tabular}{|c|c|c|c|c|c|}
\hline & & $\begin{array}{l}\text { Biom } \\
\text { Below }\end{array}$ & $\begin{array}{l}\text { ânea (k } \\
\text { ass (kg) }\end{array}$ & & \\
\hline$\overline{0}$ & 3269 & 5235 & $+60 \%$ & 4252 & 100 \\
\hline 30 & 2424 & 4837 & $+99 \%$ & 3630 & 85 \\
\hline 50 & 1916 & 3324 & $+73 \%$ & 2620 & 62 \\
\hline 70 & 1602 & 2206 & $+37 \%$ & 1904 & 45 \\
\hline & & $\begin{array}{r}\text { (c) } \mathrm{Bi} \\
T_{0} \\
\end{array}$ & $\begin{array}{c}1(\mathrm{~kg} / \mathrm{M} \\
(\mathrm{kg} / \mathrm{DM}\end{array}$ & & \\
\hline 0 & 9337 & 7538 & $-20 \%$ & 8437 & 100 \\
\hline 30 & 7502 & 7481 & 0 & 7491 & 89 \\
\hline 50 & 5706 & 6721 & $+18 \%$ & 6214 & 74 \\
\hline 70 & 4631 & 6268 & $+35 \%$ & 5450 & 65 \\
\hline
\end{tabular}


à variação sazonal da produção de biomassa (Tabela 1) podem ser explicadas por dois fatores: a) o período seco (maio a outubro) corresponde à época de maior insolação do ano nesta região (Figura 1), proporcionando maior disponibilidade de radiação solar para as plantas neste período e b) apesar de não ter sido determinado, pôde-se observar que, durante o período seco, o teor de umidade do solo nos tratamentos com 50 e $70 \%$ de sombreamento foi visivelmente superior ao dos demais, principalmente ao da testemunha.

Esta manutenção da umidade do solo, devido à menor evapotranspiração, juntamente com a maior insolação no período, proporcionou às plantas submetidas a 50 e $70 \%$ de sombreamento melhor desempenho produtivo no período seco que no período

(a) Período chuvoso

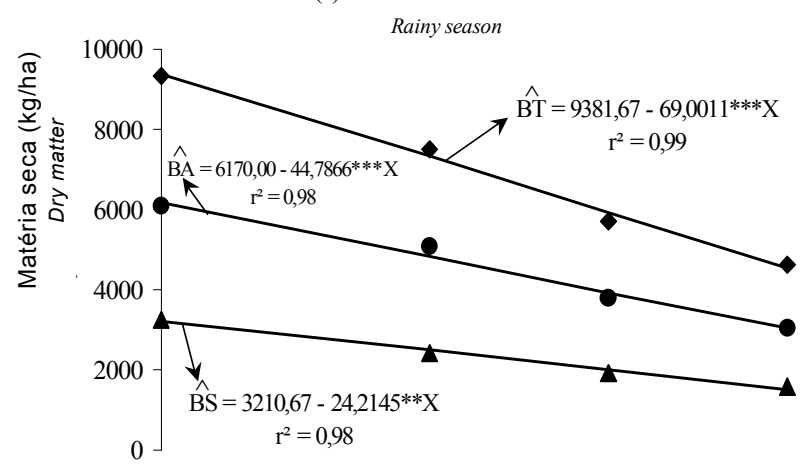

(b) Período seco

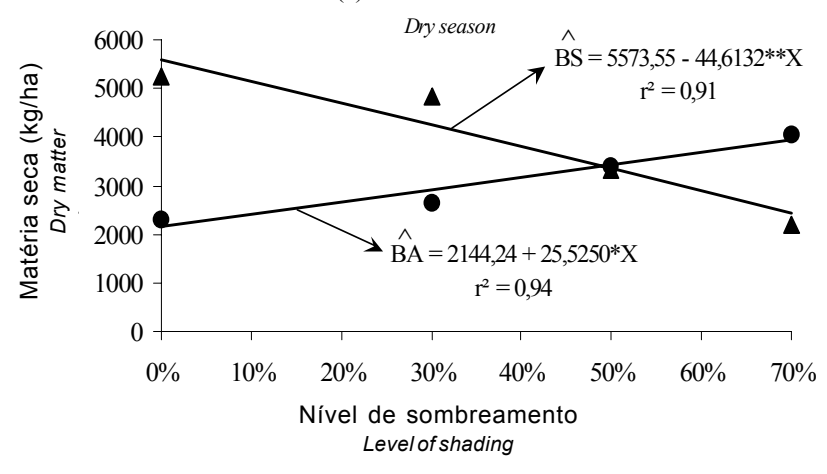

Figura 2 - Efeito de diferentes níveis de sombreamento na produção de biomassa aérea (BA), subterrânea (BS) e total (BT) de Arachis pintoi, nos períodos chuvoso e seco.

Figure 2 - Effect of different levels of shading on yield of total (BT), above (BA) and below ground biomass (BS) of the Arachis pintoi, in the rainy and dry seasons. chuvoso, visto que as suas biomassas totais aumentaram 18 e $35 \%$, respectivamente (Tabela 1c). Este fato indica também que, durante o período seco do ano, a produção forrageira nesta região é restringida apenas pelo déficit hídrico, sendo os fatores temperatura e radiação solar favoráveis ao crescimento vegetal.

Já as plantas mantidas a pleno sol e a $30 \%$ de sombreamento reduziram a biomassa aérea e aumentaram a biomassa subterrânea no período seco, em relação ao período chuvoso, sendo que a biomassa total da testemunha diminuiu $20 \%$ e a do tratamento com $30 \%$ de sombreamento se manteve estável (Tabela 1). Este crescimento preferencial do sistema radicular, em relação à parte aérea, permitindo à planta explorar maior volume de solo para absorção de água (RODRIGUES et al., 1993) e diminuir a transpiração pela menor área foliar, é uma forma de adaptação ao estresse hídrico.

A manutenção da umidade do solo, durante o período seco, é importante e positivo efeito do sombreamento, favorecendo o crescimento forrageiro neste período e diminuindo a estacionalidade da produção de forragem durante o ano. Entretanto, sob condições de sombreamento natural, este efeito pode ser minimizado, devido à competição dos componentes arbóreos.

\section{Adaptação e persistência}

Durante o período chuvoso, as plantas de $A$. pintoi apresentaram o mesmo padrão de alocação de biomassa em todos os níveis de sombreamento, com $65 \%$ da biomassa total alocada na parte aérea e 35\% no sistema radicular (Figura 3). No período seco ocorreu inversão neste padrão para as plantas mantidas a pleno sol e a $30 \%$ de sombreamento, que apresentaram, respectivamente, 70 e $65 \%$ das suas biomassas totais alocadas no sistema radicular. As plantas submetidas a $70 \%$ de sombreamento mantiveram o mesmo padrão apresentado no período chuvoso, e as submetidas a $50 \%$ de sombreamento modificaram um pouco o padrão, passando a apresentar $50 \%$ da biomassa total na parte aérea e $50 \%$ no sistema radicular.

Os resultados do período chuvoso demonstram claramente que o padrão de alocação de biomassa de $A$. pintoi não foi alterado pela redução da quantidade de luz disponível para as plantas, sendo este um fator indicativo da sua tolerância ao sombreamento. As diferenças ocorridas no período seco foram causadas pelo efeito indireto do sombreamento na manutenção da umidade do solo. Entretanto, deve-se salientar que estes resultados foram obtidos após longo período de crescimento (150 dias) sem cortes, sendo que a resposta desta 
leguminosa pode ser diferente, quando submetida a cortes mais freqüentes.

No período chuvoso, a altura das plantas de $A$. pintoi aumentou linear e positivamente, com os níveis de sombreamento, em janeiro $(\mathrm{P}<0,001)$, fevereiro $(\mathrm{P}<0,01)$ e março $(P<0,001)$, sendo que em abril e maio a altura foi semelhante em todos os níveis de sombreamento (Tabela 2). No período seco, a altura das plantas aumentou de maneira linear e positiva $(\mathrm{P}<0,001)$, com os níveis de sombreamento, nos meses de agosto, setembro e outubro. Neste período, o efeito do estresse hídrico acentuou ainda mais as diferenças entre os tratamentos.

A leguminosa A. pintoi possui hábito de crescimento estolonífero, lançando estolões horizontalmente, em todas as direções. É uma leguminosa de porte baixo, que dificilmente ultrapassa os $30 \mathrm{~cm}$ de altura. Sob sombreamento, as plantas apresentaram crescimento mais vertical, com maior alongamento do caule, maior tamanho e menor densidade de folhas. Verificou-se também que, após atingirem altura superior a $30 \mathrm{~cm}$, as plantas começavam a acamar, provavelmente por não possuírem estrutura capaz de suportar este crescimento vertical, passando a

Tabela 2 - Regressão da altura de plantas (ALT; cm) de $A$. pintoi, em relação aos níveis de sombreamento, nos períodos chuvoso e seco

Table 2 - Regression of height $(\mathrm{PH} ; \mathrm{cm})$ of $\mathrm{A}$. pintoi as on the levels of shading, in the rainy and dry season

\begin{tabular}{|c|c|c|}
\hline $\begin{array}{l}\text { Mês } \\
\text { Month }\end{array}$ & $\begin{array}{c}\text { Regressão } \\
\text { Regression } \\
\text { Período chuvoso } \\
\text { Rainy season }\end{array}$ & $\mathrm{r}^{2}$ \\
\hline $\begin{array}{l}\text { Janeiro } \\
\text { January }\end{array}$ & $\widehat{\mathrm{ALT}}=18,03+0,1425 * * * \mathrm{X}$ & 0,95 \\
\hline $\begin{array}{l}\text { Fevereiro } \\
\text { February }\end{array}$ & $\hat{\mathrm{ALT}}=23,57+0,1515^{* * \mathrm{X}}$ & 0,76 \\
\hline $\begin{array}{l}\text { Março } \\
\text { March }\end{array}$ & $\mathrm{ALT}=25,80+0,1091 * * * \mathrm{X}$ & 0,85 \\
\hline $\begin{array}{l}\text { Abril } \\
\text { April }\end{array}$ & $\hat{\mathrm{ALT}}=\overline{\mathrm{Y}}=29,87$ & $\mathrm{~ns}$ \\
\hline $\begin{array}{l}\text { Maio } \\
\text { May }\end{array}$ & $\hat{\mathrm{ALT}}=\overline{\mathrm{Y}}=24,75$ & $\mathrm{~ns}$ \\
\hline & $\begin{array}{l}\text { Período seco } \\
\text { Dry season }\end{array}$ & \\
\hline $\begin{array}{l}\text { Agosto } \\
\text { August }\end{array}$ & $\widehat{\mathrm{ALT}}=9,25+0,2250 * * * \mathrm{X}$ & 0,91 \\
\hline $\begin{array}{l}\text { Setembro } \\
\text { September }\end{array}$ & $\mathrm{ALT}=8,74+0,3119 * * * \mathrm{X}$ & 0,95 \\
\hline $\begin{array}{l}\text { Outubro } \\
\text { October }\end{array}$ & $\mathrm{ALT}=8,37+0,2983 * * * \mathrm{X}$ & 0,98 \\
\hline
\end{tabular}

crescer lateralmente (Figura 4).

A leguminosa $A$. pintoi, com relação às características cobertura do solo e vigor das plantas, apresentou no período chuvoso comportamento semelhante nos diferentes níveis de sombreamento a que foi submetida. Já no período seco, houve efeito linear positivo ( $\mathrm{P}<0,01)$, com os níveis de sombreamento, para as duas características (Tabela 3 ). Contudo, os resultados deste último período foram conseqüência do efeito indireto do sombreamento na manutenção da umidade do solo, assim como ocorreu para as demais características avaliadas.

Os resultados obtidos permitem sugerir que futuros trabalhos de avaliação da tolerância de forrageiras ao sombreamento devem: a) levar em consideração as variações climáticas sazonais de cada local, pois se as avaliações forem realizadas em apenas uma estação do ano, pode-se estar incorrendo no erro de subestimar ou superestimar a tolerância ao sombreamento de determinada forrageira e b) avaliar não apenas a produção de forragem, mas também a biomassa subterrânea, para obter dados confiáveis sobre a persistência da forrageira, pois, de acordo com WONG (1991), a tolerância ao sombreamento de determinada espécie forrageira é refletida pela sua capacidade de produção e persistência sob determinado nível de sombreamento.

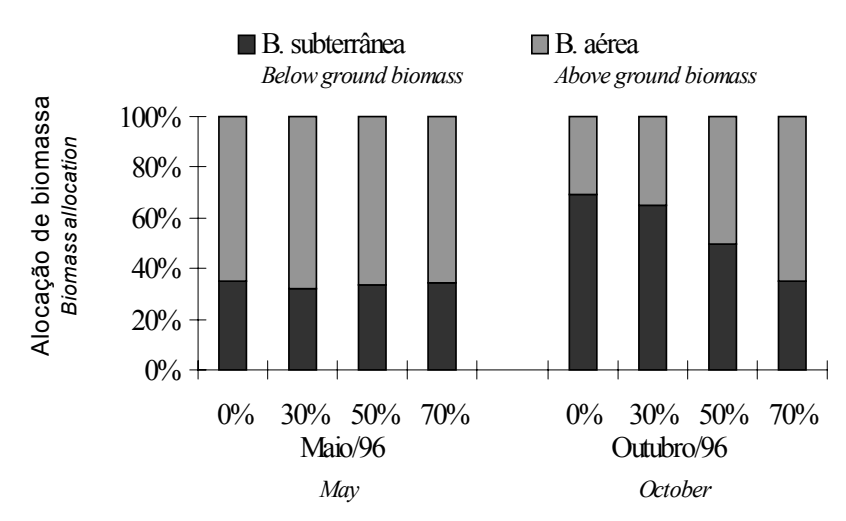

Figura 3 - Alocação da biomassa de Arachis pintoi, submetido a diferentes níveis de sombreamento, no final do período chuvoso (Maio/96) e do período seco (Outubro/96).

Figure 3 - Biomass allocation of Arachis pintoi, submitted to different levels of shading, at the end of the rainy season (May/96) and dry season (October/96). 
Tabela 3 - Cobertura do solo e vigor de A. pintoi submetido a diferentes níveis de sombreamento, no final do período chuvoso (Mai/96) e do período seco (Out/96)

Table 3 - Ground cover and vigor of A. pintoi, submitted to different levels of shading, at the end of the rainy season (May/96) and dry season (Oct/96)

\begin{tabular}{|c|c|c|c|c|}
\hline \multirow{2}{*}{$\begin{array}{l}\text { Nível de sombra, } \\
\text { Level of shade }\end{array}$} & \multicolumn{2}{|c|}{$\begin{array}{c}\text { Cobertura do solo }(\mathrm{CS} ; \%) \\
\text { Ground cover }(G C ; \%)\end{array}$} & \multicolumn{2}{|c|}{$\begin{array}{c}\text { Vigor das plantas }^{1}(\mathrm{VP}) \\
\text { Plant vigor }^{1}(P V)\end{array}$} \\
\hline & $\begin{array}{c}\text { Mai/96 } \\
\text { May }\end{array}$ & $\begin{array}{c}\text { Out/96 } \\
\text { Oct }\end{array}$ & $\begin{array}{l}\text { Mai/96 } \\
\text { May }\end{array}$ & $\begin{array}{c}\text { Out } / 96 \\
\text { Oct }\end{array}$ \\
\hline$\overline{0}$ & 90 & 75 & 4,0 & 3,00 \\
\hline 30 & 90 & 80 & 4,0 & 3,00 \\
\hline 50 & 85 & 85 & 4,0 & 3,75 \\
\hline 70 & $\wedge \quad 90$ & 90 & $\wedge \quad 4,0$ & 4,00 \\
\hline $\begin{array}{l}\text { Regressão } \\
\text { Regression }\end{array}$ & $\mathrm{CS}=\overline{\mathrm{Y}}=88,75$ & $\mathrm{CS}=74,44+0,215 * * \mathrm{X}$ & $\mathrm{VP}=\overline{\mathrm{Y}}=4,0$ & $\mathrm{VP}=2,85+0,0156^{* * \mathrm{X}}$ \\
\hline $\mathrm{r}^{2}$ & & 0,99 & & 0,82 \\
\hline
\end{tabular}

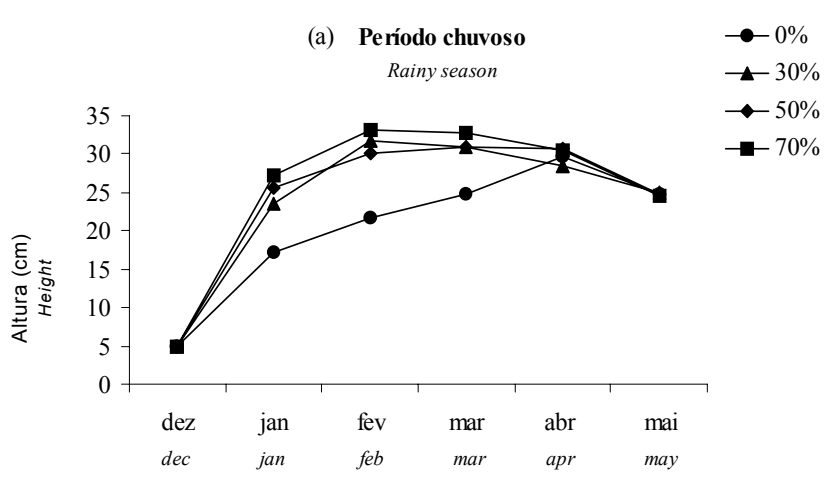

(b) Período seco Dry season

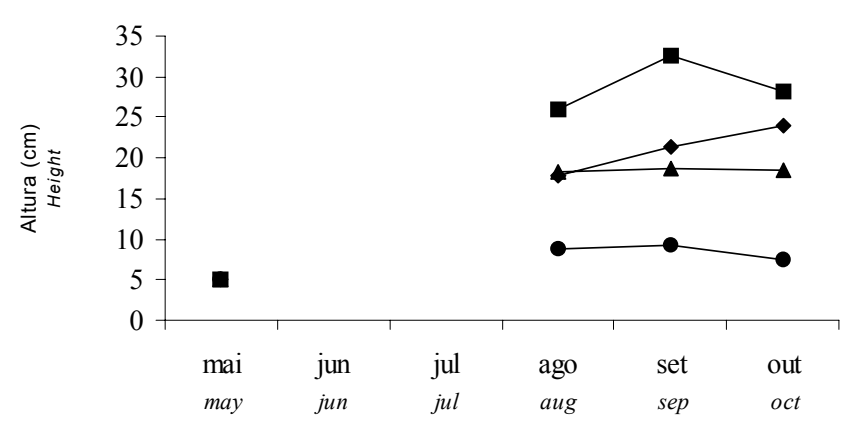

Figura 4 - Altura das plantas de Arachis pintoi, submetido a diferentes níveis de sombreamento, durante os períodos chuvoso e seco.

Figure 4 - Plant height of Arachis pintoi, submitted to different levels of shading, during the rainy and dry seasons.

\section{Conclusões}

A leguminosa $A$. pintoi apresentou boa adaptação, produtividade e persistência nos diferentes níveis de sombreamento a que foi submetida, nas condições de Rio Branco, Acre. Este fato, aliado a outras características favoráveis desta leguminosa, indica ser possível a sua utilização não somente como cobertura do solo em sistemas agroflorestais, mas também para a produção de forragem em sistemas silvipastoris.

Torna-se necessário, entretanto, verificar a sua persistência quando submetida a regimes mais intensos de corte ou sob pastejo direto, visto que a biomassa subterrânea diminuiu com o aumento dos níveis de sombreamento, o que pode comprometer a sua capacidade de recuperação nos níveis mais altos de sombreamento. Outro fator que também necessita ser investigado é a produção de sementes em condições de sombreamento, a qual também influi na persistência da leguminosa.

\section{Referências Bibliográficas}

ANDRADE, C.M.S., VALENTIM, J.F. 1996. Efeito de diferentes niveis de sombreamento na produtividade e persistência de Arachis pintoi em Rio Branco, Acre. Rio Branco: EMBRAPA/CPAF-Acre, 4p. (EMBRAPA/CPAF-Acre. Pesquisa em Andamento, 80).

de la CRUZ, R., SUÁREZ, S., FERGUSON, J. E. 1994. The contribution of Arachis pintoi as a ground cover in some farming systems of Tropical America. In: KERRIDGE, P. C. e HARDY, B. (eds.). Biology and Agronomy of Forage Arachis. Cali, CIAT, Chapter 9, p.102-108. 
Rev. bras. zootec.

LASCANO, C. E. 1994. Nutritive value and animal production of forage Arachis. In: KERRIDGE, P. C., HARDY, B. (eds.). Biology and Agronomy of Forage Arachis. Cali, CIAT, Chapter 10, p.109-121.

PIZARRO, E. A., RINCÓN, A. 1994. Regional experience with forage Arachis in South America. In: KERRIDGE, P. C., HARDY, B. (eds.). Biology and Agronomy of Forage Arachis. Cali, CIAT, Chapter 13, p.144-157.

RODRIGUES, T.J.D., RODRIGUES, L.R.A., REIS, R.A. Adaptação de plantas forrageiras às condições adversas. In: SIMPÓSIO SOBRE ECOSSISTEMA DE PASTAGENS, 2, 1993, Jaboticabal, SP. Anais... Jaboticabal: FUNEP, 1993, p.17-61.

SAS/STAT User's guide. 1989. Version 6, 4.ed. Cary: SAS Institute, v.1, 943p.

SKERMAN, P. J. 1977. Tropicalforagelegumes. Roma, FAO, 609p.
VALENTIM, J. F. Avaliação do potencial forrageiro de Arachis spp. nas condições ambientais do Acre. In: REUNIÃO ANUAL DA SOCIEDADE BRASILEIRA DE ZOOTECNIA, 34, 1997, Juiz de Fora, MG. Anais... Juiz de Fora: SBZ, 1997, 2:30-32.

WONG, C.C. 1991. Shade tolerance of tropical forages: a review. In: SHELTON, H.M., STÜR, W.W. (eds.). Forages for plantation crops - Proceedings, n.32. Canberra: ACIAR, p. 64-69 (Proceedings of a Workshop, 1990, Bali).

Recebido em: 16/09/97

Aceito em: 26/11/98 